\title{
Communications
}

Chemical Logic Gates

DOI: 10.1002/anie.201104228

\section{From Virtual to Physical: Integration of Chemical Logic} Gates**

Ruslan Guliyev, Seyma Ozturk, Ziya Kostereli, and Engin U. Akkaya*

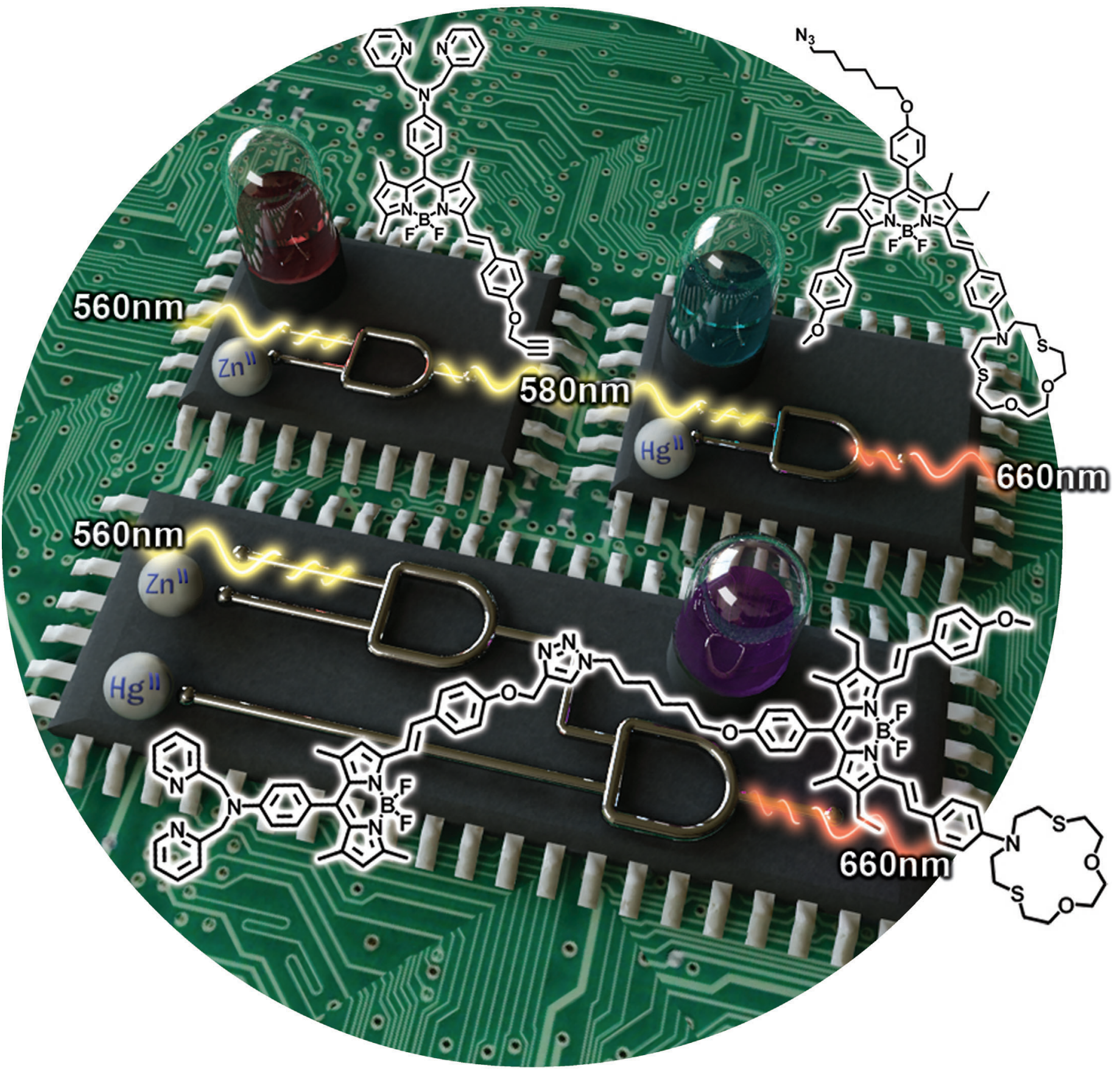

\section{Angewandte}

\section{Chemie}


Logic gates are fundamental building blocks of silicon circuitry. Current technology used in integrated circuit design is fast approaching its physical limits, and this "impending doom" scenario ${ }^{[1]}$ has led many to consider potential alternatives in information processing. Bottom-up approaches, including molecular mimicry of logic gates with ion-responsive molecules, have received considerable attention since 1993, following the pioneering work of de Silva et al. ${ }^{[2]}$ In nearly two decades, all 16 fundamental logic gates ${ }^{[3]}$ and higher functions such as half-adder/subtractor ${ }^{[3,4]}$ multiplexer, ${ }^{[5]}$ password protection, ${ }^{[6]}$ encoder/decoder, ${ }^{[7]}$ and sequential logic ${ }^{[8]}$ were demonstrated. These higher functions require considerable degrees of integration or concatenation between logic gates if they are to be implemented using standard practice of semiconductor technology. We also appreciate the fact that molecular logic need not be confined within the reigning paradigms of silicon-based information processing. Nevertheless, physical integration of chemical (molecular) logic gates is especially important for rational design and implementation towards advanced molecularscale computing. However, with chemical logic gates, almost all of the integration or concatenation is "functional". In other words, the outputs at various channels (for example, at different wavelengths) are typically analyzed, and a concatenated set of logic gates is then proposed to be acting on the inputs to generate the apparent output sequence. A more fitting term for this class of integration might be "virtual". While this approach is highly convenient and reconfigurable/ superposed logic gates can be quite useful, it is nevertheless obvious that, at some point, there has to be simple and general methodologies for physically (as opposed to virtually) bringing together independently working molecular logic gates to function together as concatenated/integrated logic gates.

Previous work toward concatenated logic gates was often based on enzymatically coupled systems. ${ }^{[9]}$ While these systems involve interesting reinterpretations or rewiring of enzymatic pathways and other biomolecular interactions, we will need to have more general and broadly applicable methodologies for de novo concatenation on the way to more capable integrated systems.

In recent years, a few examples of chemical cascading, or integration schemes, were proposed. ${ }^{[10]}$ In a promising recent report by the Raymo and Credi groups, ${ }^{[10 \mathrm{c}]}$ a merocyanine derivative that photochemically produces hydrogen ions was

[*] R. Guliyev, ${ }^{[+]}$Prof. Dr. E. U. Akkaya

UNAM-Institute of Materials Science and Nanotechnology Bilkent University, Ankara 06800 (Turkey)

E-mail: eua@fen.bilkent.edu.tr

S. Ozturk, ${ }^{[+]}$Z. Kostereli, ${ }^{[+]}$Prof. Dr. E. U. Akkaya

Department of Chemistry

Bilkent University, 06800 Ankara (Turkey)

$\left[{ }^{+}\right]$These authors contributed equally to this work.

[***] We are grateful for funding by Turkish Academy of Sciences (TUBA) and State Planning Organization (DPT). R.G. and S.O. thank TUBITAK for graduate scholarships. We also thank Bora Bilgic for his creative graphics contributions.

Supporting information for this article is available on the WWWW under http://dx.doi.org/10.1002/anie.201104228. linked to a ruthenium complex, resulting in a serial connection between two logic operations. However, clear demonstration (with non-additive inputs and large digital-on-off changes) of independently existing and functional logic gates, physically coupled together and thus functioning in an integrated fashion, remained elusive.

Herein, we propose two possible ways of achieving integration of independently functioning chemical logic gates: one approach makes use of the inner filter effect (IFE), which is modulated photochromically, and the other one is based on increased efficiency of Förster type intramolecular energy transfer (excitation energy transfer, EET) compared to the intermolecular energy transfer (other factors remaining unchanged). Utility of IFE in molecular logic was shown earlier ${ }^{[11]}$ in that work distinct compartmentalization of the logic molecules was needed, and this was achieved on a macroscopic level by placing them in separate cuvettes. In our IFE-based approach, we chose thionine as the photochromic agent (Scheme 1). Thionine, although not utilized in any logic gate design to date, could be highly useful in optical

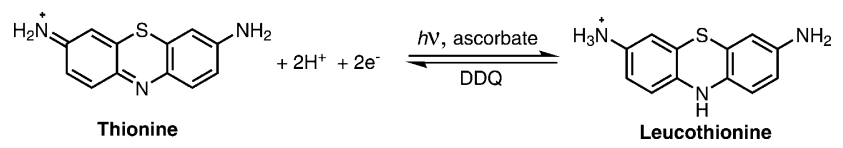

Scheme 1. Reversible photochemical conversion of thionine into the leucothionine form. DDQ =2,3-dichloro-5,6-dicyano-1,4-benzoquinone.

concatenation of logic gates. Thionine in the purple-colored solution (absorption maximum at $590 \mathrm{~nm}$ ) can be photochemically reduced by many mild reducing agents, such as sodium ascorbate, to yield the colorless leuco form. The clear solution with a higher transmittance (Figure 1) will allow sufficient intensity of light at another wavelength $(560 \mathrm{~nm})$ to interrogate the second logic gate (and serve as an input) present in the same solution.

Herein, the first independent AND logic gate is the thionine molecule: the output is the transmitted monochromatic light at $560 \mathrm{~nm}$. This output will be high only if both photonic inputs, that is, broadband white light and $560 \mathrm{~nm}$ light, are introduced to the system. (Figure 2). The other AND logic gate we propose in this scheme is related to compound $\mathbf{2}$ (Scheme 2). It is a styryl-bodipy derivative with a dipicolylamine (DPA) group tethered at the meso-(8) position. Its fluorescence is quenched through an efficient photoinduced electron transfer (PeT) process, but high emission intensity is recovered when certain metal ions such as $\mathrm{Zn}^{\mathrm{II}}$ are added. Both inputs (light at $560 \mathrm{~nm}$ and $\mathrm{Zn}^{\mathrm{II}}$ ions) need to be high for output to be high (1). Naturally, this second AND gate works independently as well. When we bring together these two gates in solution, the output of the first gate (thionine) will be one of the inputs of the gate 2 . Thus, in the mixture of two AND logic components, the two gates are integrated through photochemical modulation of the inner filter effect. Reversibility of the photochromic response was clearly demonstrated (Figure 3). It is also important to show 


\section{Communications}
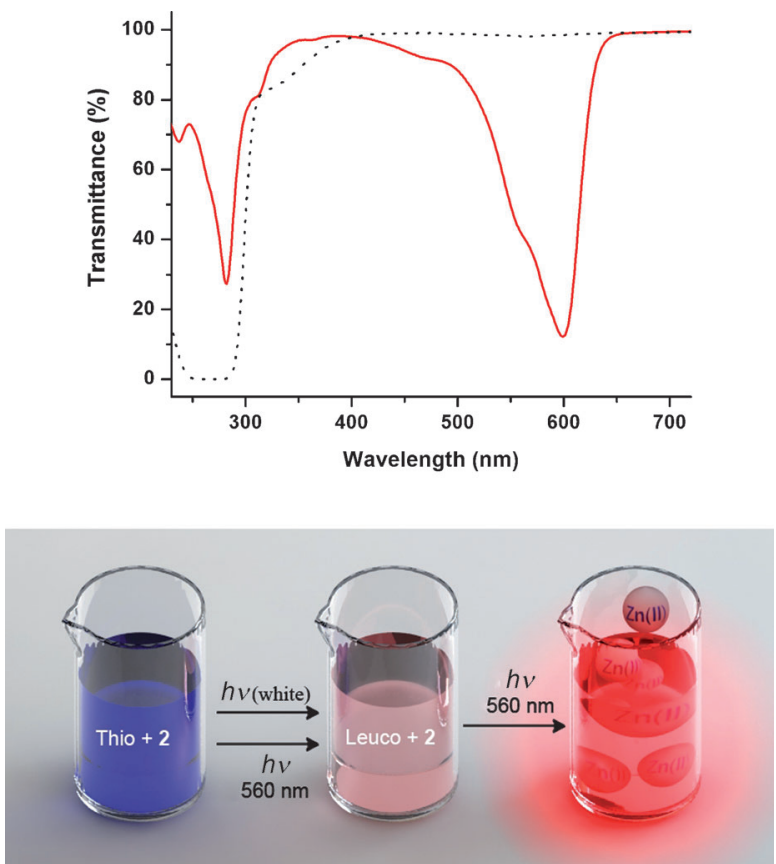

Figure 1. Top: Transmission spectra of thionine (red, solid curve) and leucothionine (black, dashed curve) $12.5 \mu \mathrm{m}$ in methanol. The leuco form was obtained by exposing the thionine solution to broadband white light in the presence of sodium ascorbate as a reducing agent. Bottom: A representation of the operation of the coupled AND logic gates in the IFE integration scheme.

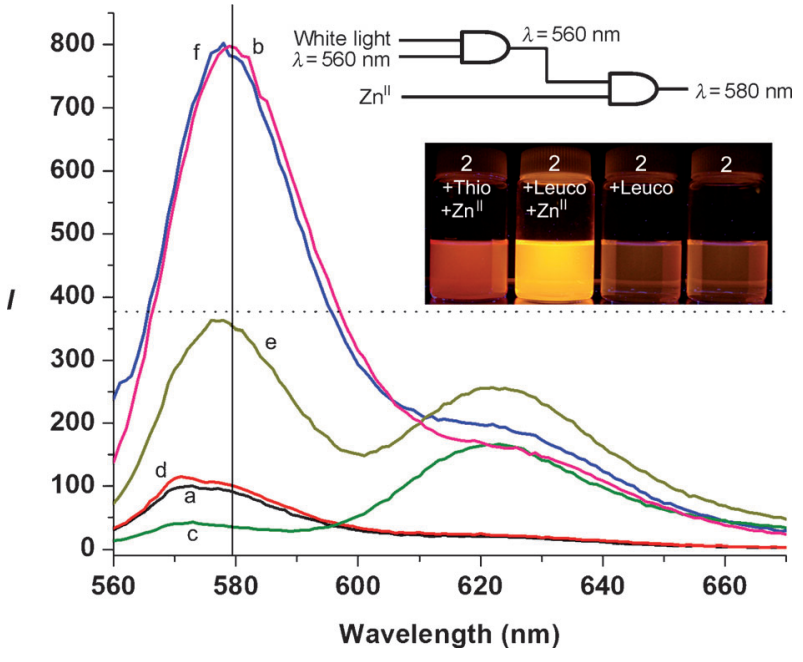

Figure 2. Operation of the integrated logic gates (IFE) as demonstrated by the emission spectra of compound $2(2.2 \mu \mathrm{M})$ in the presence of thionine/leucothionine $(12.5 \mu \mathrm{M})$ in methanol. a) $\mathbf{2}$ alone, b) $\mathbf{2}+\mathrm{Zn}^{\prime \prime}$, c) $\mathbf{2}+$ thionine, d) $\mathbf{2}+$ leucothionine ((c) + white light) e) $\mathbf{2}+$ thionine $+\mathrm{Zn}^{\prime \prime}$, f) $\mathbf{2}+$ leucothionine $+\mathrm{Zn}^{\text {"I }}((\mathrm{e})+$ white light $)$. $\mathbf{Z n}$ ions were added in the form of perchlorate salt at $22.0 \mu \mathrm{M}$ concen tration. $\lambda_{\mathrm{ex}}=560 \mathrm{~nm}$, slit width $=5 \mathrm{~nm}$.
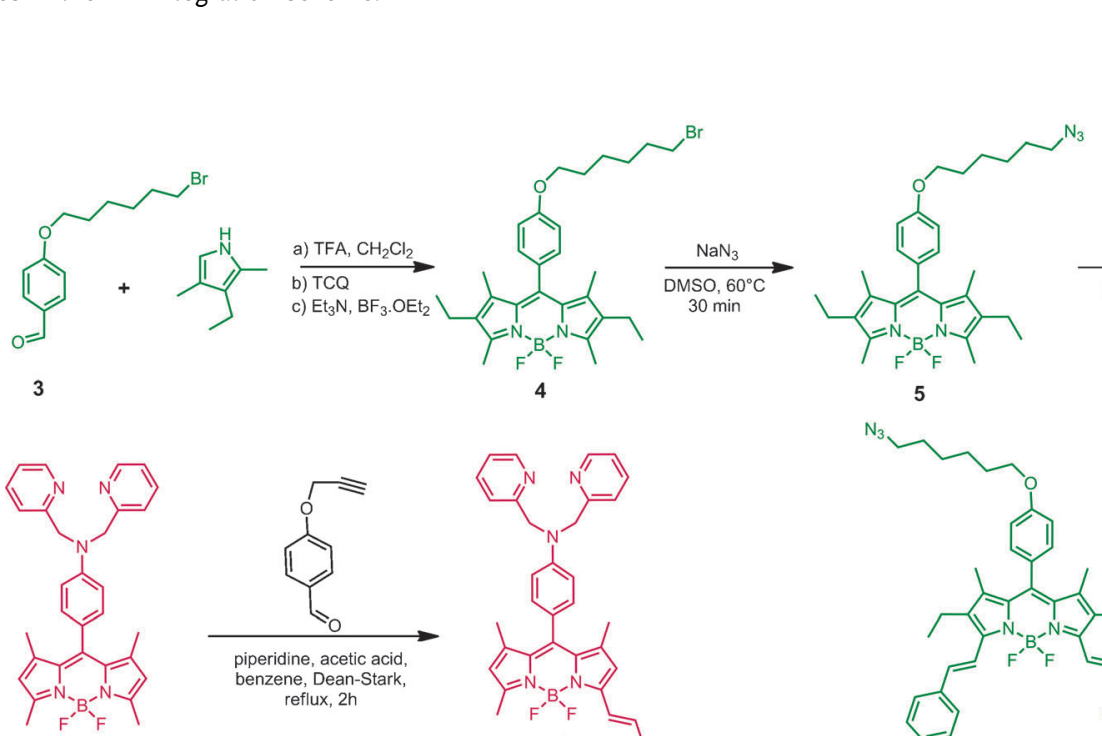

1

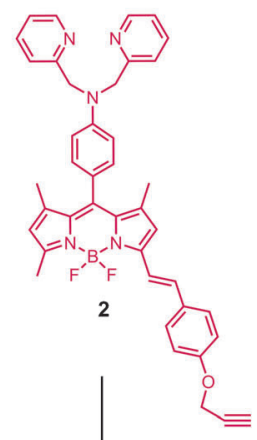

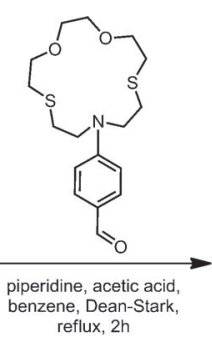

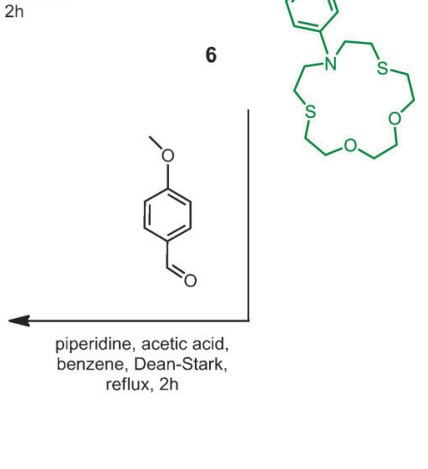

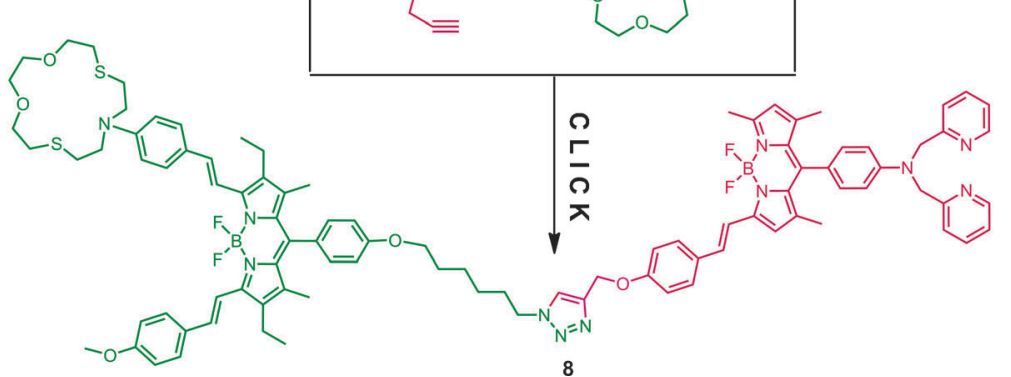

Scheme 2. Synthesis of logic-gate modules and the final click reaction for the integrated logic compound 8 . TFA $=$ trifluoroacetic acid, $\mathrm{TCQ}=2,3,5,6$-tetrachloro-1,4-benzoquinone. 


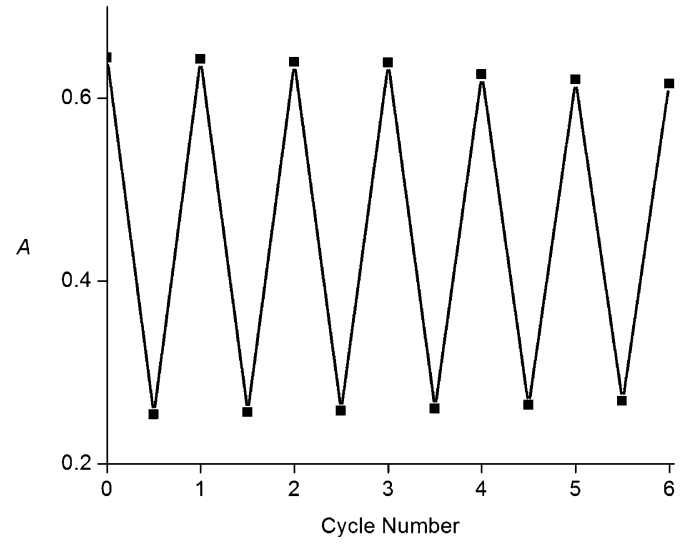

Figure 3. Reversibility of the thionine photochromic response. The reduced leuco form of thionine $(12.5 \mu \mathrm{M})$, which is produced by photochemical reduction, can be transformed back to the original chromophore by DDQ oxidation. The reduction-oxidation cycling can be repeated many times in the presence of the second logic compound $2(2.2 \mu \mathrm{M})$.

that with broadband white light alone, the emission from the gate $\mathbf{2}$ (styryl-bodipy) has to be low, and this result has been demonstrated as well. On standing at room temperature in the presence of excess ascorbate, the oxidized form can be accessed by the addition of DDQ or by air oxidation. It is interesting to note that DDQ and ascorbate do not react directly under the conditions of the study. In summary, two independent AND logic gates can be coerced to work in an integrated fashion by simply mixing them in solution.

The idea of using excitation energy transfer for the integration of logic gates was proposed in a conjectural article. $^{[12]}$ In our energy transfer (EET) based approach however, two chemical gates were again designed to act separately and independently as two distinct AND gates, without interference or cross-talk. The design of these chemical logic-gate molecules includes "clickable" azide and terminal alkyne units. The first AND gate is the same as the second one used in the previous scheme (compound 2). The other is also a monostyryl derivative (7), but since it has an azathiacrown moiety attached through its amine nitrogen atom (essentially a dialkylamino group), increased chargetransfer characteristics lead to longer-wavelength absorption and emission (Figure 4). Compound 7 also acts as an AND logic gate, with a photonic (light at $580 \mathrm{~nm}$ ) and ionic $\left(\mathrm{Hg}^{\mathrm{II}}\right)$ input. Only when both inputs are present is strong red emission at $660 \mathrm{~nm}$ produced. When compounds $\mathbf{2}$ and $\mathbf{7}$ are "clicked" together with Huisgen cycloaddition, the obtained product $(\mathbf{8})$ is in fact an ion-modulated energy-transfer cassette. In this molecule, the photonic output at $660 \mathrm{~nm}$ is only generated when all three inputs $\left(h v \lambda=560 \mathrm{~nm}, \mathrm{Zn}^{\mathrm{II}}\right.$, and $\mathrm{Hg}^{\mathrm{II}}$ ) are present (high). In all other combinations, the emission at $660 \mathrm{~nm}$ is low (Figure 5). The emission at the red channel is dependent on the PeT efficiency of the module derived from the first logic gate (2). The excitation at $560 \mathrm{~nm}$ results in excitation of that particular fluorophore, but in the absence of $\mathrm{Zn}^{\mathrm{II}}$, energy transfer efficiency is drastically reduced. When $\mathrm{Zn}^{\mathrm{II}}$ is present, PeT is blocked, and excitation

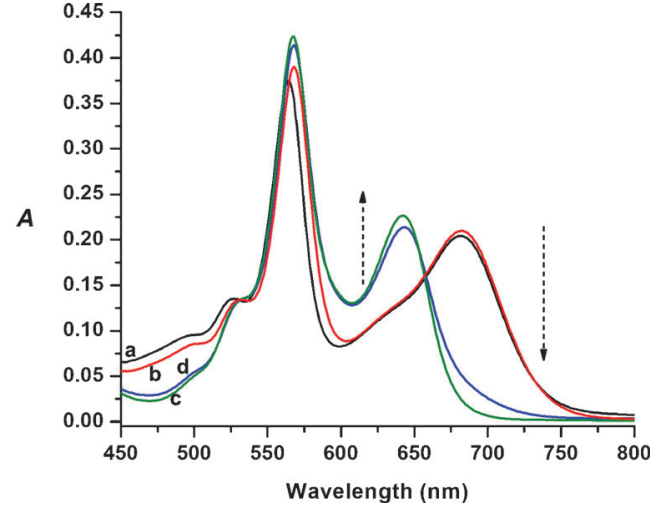

Figure 4. Absorbance spectra of Compound $8(3.0 \mu \mathrm{M})$ in acetonitrile in the presence of $\mathrm{Zn}^{\prime \prime}$ and $\mathrm{Hg}$ " cations (20.0 and $10 \mu \mathrm{M}$, respectively). a) 8 , b) $8+\mathrm{Zn}^{\prime \prime}$, c) $8+\mathrm{Hg}^{\prime \prime}$, d) $8+\mathrm{Zn}^{\prime \prime}+\mathrm{Hg}^{\prime \prime}$.

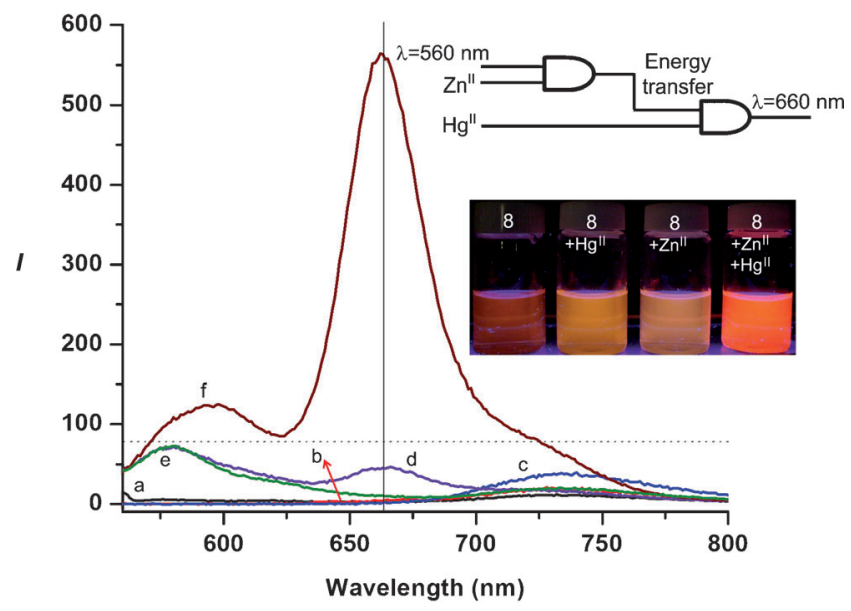

Figure 5. Operation of the integrated logic gates (EET) as demonstrated by the emission spectra of compound $8(3.0 \mu \mathrm{M})$ in acetonitrile in the presence of $\mathrm{Zn}^{\prime \prime}$ and $\mathrm{Hg}^{\prime \prime}$ cations (20.0 and $10 \mu \mathrm{M}$, respectively). $\lambda_{\mathrm{ex}}=560 \mathrm{~nm}$, slit width=5-2.5 nm. a)8@560 nm, b)8@640nm; c) $8 @ 680 \mathrm{~nm}$; d) 8+Hg"@560nm; e) 8+Zn" @560nm; f) $8+\mathrm{Hg}^{\prime \prime}+\mathrm{Zn}$ "@560nm.

energy is transferred to the second module. This energy transfer is evidenced both by quantum yield ( 2 vs. 8 , the donor data) and lifetime changes (Table 1). The emission quantum yield of the donor module $\mathbf{2}$ is 0.1 (due to effective PeT), but increases to 0.71 on $\mathrm{Zn}^{\mathrm{II}}$ addition. In the "click" integrated logic molecule 8, the donor is hardly emissive $\left(\Phi_{\mathrm{F}}=0.002\right.$, owing to effective Förster type energy transfer). The second module (acceptor) derived from compound 7, even when energy transfer is effective, does not fluoresce brightly because of strong intramolecular charge transfer chargedonor characteristics of the dialkylamino group. When the final input $\left(\mathrm{Hg}^{\mathrm{II}}\right)$ is added, then strong red emission is observed (Figure 5).

Since the ligands in both of the logic gate modules are highly selective, there is no crosstalk; the metal ions do not interfere or target the "wrong" ligand at the concentrations of the study, at least to an extent to cause problems in signal 
Table 1: Photophysical parameters for the EET integration scheme.

\begin{tabular}{|c|c|c|c|c|c|c|c|c|}
\hline \multirow[t]{2}{*}{ Compound } & \multicolumn{2}{|c|}{$\lambda_{\max }$} & \multicolumn{2}{|c|}{$\varepsilon_{\max }$} & \multicolumn{2}{|c|}{$\Phi^{[a]}$} & \multicolumn{2}{|c|}{$\tau[\mathrm{ns}]^{[\mathrm{b}]}$} \\
\hline & $\mathrm{D}^{[c]}$ & $A^{[c]}$ & $\mathrm{D}$ & A & D & A & $\tau_{1}$ & $\tau_{2}$ \\
\hline 2 & \multicolumn{2}{|c|}{562} & \multicolumn{2}{|c|}{84000} & \multicolumn{2}{|c|}{0.1} & \multicolumn{2}{|c|}{3.91} \\
\hline $2+\mathrm{Zn}^{\prime \prime}$ & \multicolumn{2}{|c|}{562} & \multicolumn{2}{|c|}{84000} & \multicolumn{2}{|c|}{0.71} & \multicolumn{2}{|c|}{3.95} \\
\hline 6 & \multicolumn{2}{|c|}{611} & \multicolumn{2}{|c|}{51000} & \multicolumn{2}{|c|}{0.13} & \multicolumn{2}{|c|}{3.15} \\
\hline $6+\mathrm{Hg}^{\prime \prime}$ & \multicolumn{2}{|c|}{573} & \multicolumn{2}{|c|}{51000} & \multicolumn{2}{|c|}{0.56} & \multicolumn{2}{|c|}{ - } \\
\hline 7 & \multicolumn{2}{|c|}{680} & \multicolumn{2}{|c|}{52000} & \multicolumn{2}{|c|}{0.036} & \multicolumn{2}{|c|}{2.01} \\
\hline $7+\mathrm{Hg}^{11}$ & \multicolumn{2}{|c|}{642} & \multicolumn{2}{|c|}{58000} & \multicolumn{2}{|c|}{0.24} & \multicolumn{2}{|c|}{-} \\
\hline 8 & 563 & 682 & 125300 & 68000 & 0.002 & 0.004 & 0.32 & 3.63 \\
\hline $8+Z^{\prime \prime}$ & 567 & 681 & 125300 & 67300 & 0.024 & 0.015 & 0.71 & 3.58 \\
\hline $8+\mathrm{Zn}^{\prime \prime}+\mathrm{Hg}^{\prime \prime}$ & 567 & 642 & 137600 & 71000 & 0.036 & 0.190 & 0.82 & 3.70 \\
\hline
\end{tabular}

[a] Quantum yields for all compounds were determined in reference to Sulforhodamine 101 ( $\Phi=0.90$ in ethanol). [b] Emission lifetimes $(\tau)$, unless two numbers are listed, correspond to single-exponential decays. Compound 2 was excited at $567 \mathrm{~nm}, 6$ at $610 \mathrm{~nm}, 7$ at $680 \mathrm{~nm}$, and 8 at $575 \mathrm{~nm}$. [c] D stands for the energy donor moiety, and A stands for the acceptor moiety. Data under these columns are related to these molecular units

evaluation. Binding constants of the ligand-metal ion pairs support this argument and were reported. ${ }^{[4 \mathrm{n}]}$ The absorbance spectra obtained for the integrated logic compound $\mathbf{8}$ under various conditions (Figure 3 ) shows this result unequivocally. $\mathrm{Zn}^{\mathrm{II}}$ ions do not bind to the azathiacrown ligand.

In conclusion, energy transfer (EET) and modulation of the inner filter effect (IFE) offer two possible methodologies for concatenation of two logic gates. The EET approach is particularly appealing because it involves physical connection of two logic gates through a chemical reaction. There are still issues to be addressed, such as the maximum number of gates that can be integrated based on an EET approach, but even the slightest improvements in mimicking silicon circuitry may yield huge leaps of advance owing to the molecular nature of these particular designs. ${ }^{[3 \mathrm{k}]}$ While other approaches, including self-assembling components, are possible, we are confident that clickable molecular logic gates are highly promising. Demonstration of more complex examples of physically integrated logic gates is to be expected. Our work along those lines is in progress.

Received: June 19, 2011

Published online: August 25, 2011

Keywords: concatenation · energy transfer - fluorescence logic gates $\cdot$ sensors

[1] V. V. Zhirnov, R. K. Cavin, J. A. Hutchby, G. I. Bourianoff, Proc. IEEE 2003, 91, 1934-1939.

[2] A. P. de Silva, H. Q. N. Gunaratne, C. P. McCoy, Nature 1993, $364,42-44$.

[3] a) A. Credi, V. Balzani, S. J. Langford, J. F. Stoddart, J. Am. Chem. Soc. 1997, 119, 2679-2681; b) H. T. Baytekin, E. U. Akkaya, Org. Lett. 2000, 2, 1725-1727; c) A. P. de Silva, N. D. McClenaghan, Chem. Eur. J. 2002, 8, 4935-4945; d) A. P. de Silva, M. R. James, B. O. F. McKinney, P. A. Pears, S. M. Weir, Nat. Mater. 2006, 5, 787-790; e) A. P. de Silva, S. S. K. de Silva, N. C. W. Goonesekera, H. Q. N Gunaratne, P. L. M.
Lynch, K. R. Nesbitt, S. T. Patuwathavithana, N. L. D. S. Ramyalal, J. Am. Chem. Soc. 2007, 129, 3050-3051; f) A. P. de Silva, S. Uchiyama, Nat. Nanotechnol. 2007, 2, 399-410; g) M. Yuan, W. Zhou, X. Liu, M. Zhu, J. Li, X. Yin, H. Zheng, Z. Zuo, C. Ouyang, H. Liu, Y. Li, D. Zhu, J. Org. Chem. 2008, 73, 50085014; h) K. Szacilowski, Chem. Rev. 2008, 108, 3481-3548; i) N. Kaur, N. Singh, D. Cairns, J. F. Callan, Org. Lett. 2009, 11, $2229-$ 2232 ; j) H. Komatsu, S. Matsumoto, S. Tamaru, K. Kaneko, M. Ikeda, I. Hamachi, J. Am. Chem. Soc. 2009, 131, 5580-5585; k) S. Ozlem, E. U. Akkaya, J. Am. Chem. Soc. 2009, 131, 48-49; 1) J. Andreasson, U. Pischel, Chem. Soc. Rev. 2010, 39, 174-188.

[4] a) A. P. de Silva, N. D. McClenaghan, J. Am. Chem. Soc. 2000, 122, 3965-3966; b) S. J. Langford, T. Yann, J. Am. Chem. Soc. 2003, 125, 11198-11199; c) W. Jiang, H. Zhang, Y. Liu, Front. Chem. China 2009, 4, 292-298; d) D. Margulies, G. Melman, C. E. Felder, R. Arad-Yellin, A. Shanzer, J. Am. Chem. Soc. 2004, 126, 15400-15401; e) A. P. de Silva, N. D. McClenaghan, Chem. Eur. J. 2004, 10, 574-586; f) A. Coskun, E. Deniz, E. U. Akkaya, Org. Lett. 2005, 7, 5187-5189; g) D. Margulies, G. Melman, A. Shanzer, Nat. Mater. 2005, 4, 768-771; h) J. Andreasson, S. D. Straight, G. Kodis, C. D. Park, M. Hambourger, M. Gervaldo, B. Albinsson, T. A. Moore, A. L. Moore, D. Gust, J. Am. Chem. Soc. 2006, 128, 16259-16265; i) U. Pischel, Angew. Chem. 2007, 119, 4100-4115; Angew. Chem. Int. Ed. 2007, 46, 4026-4040; j) S. Z. Kou, H. N. Lee, D. Van Noort, K. M. K. Swamy, S. H. Kim, J. H. Soh, K. M. Lee, S. W. Nam, J. Yoon, S. Park, Angew. Chem. 2008, 120, 886-890; Angew. Chem. Int. Ed. 2008, 47, 872-876; k) L. Zhang, W. A. Whitfield, L. Zhu, Chem. Commun. 2008, 1880-1882; 1) N. Wagner, G. Ashkenasy, Chem. Eur. J. 2009, 15, 1765-1775; m) S. Kumar, V. Luxami, R. Saini, D. Kaur, Chem. Commun. 2009, 3044-3046; n) O. A. Bozdemir, R. Guliyev, O. Buyukcakir, S. Selcuk, S. Kolemen, G. Gulseren, T. Nalbantoglu, H. Boyaci, E. U. Akkaya, J. Am. Chem. Soc. 2010, 132, 8029-8036; o) D.-H. Qu, Q. C. Wang, H. Tian, Angew. Chem. 2005, 117, 5430-5433; Angew. Chem. Int. Ed. 2005, 44, 5296-5299.

[5] J. Andreasson, S. D. Straight, S. Bandyopadhyay, R. H. Mitchell, T. A. Moore, A. L. Moore, D. Gust, Angew. Chem. 2007, 119, 976-979; Angew. Chem. Int. Ed. 2007, 46, 958-961; b) M. Amelia, M. Baroccini, A. Credi, Angew. Chem. 2008, 120, 63366339; Angew. Chem. Int. Ed. 2008, 47, 6240-6243.

[6] a) Z. Guo, W. Zhu, L. Shen, H. Tian, Angew. Chem. 2007, 119, 5645-5649; Angew. Chem. Int. Ed. 2007, 46, 5549-5553; b) D. Margulies, C. E. Felder, G. Melman, A. Shanzer, J. Am. Chem. Soc. 2007, 129, 347-354; c) W. Sun, C. Zhou, C. Xu, C. J. Fang, C. Zhang, Z. X. Li, C. H. Yan, Chem. Eur. J. 2008, 14, $6342-$ 6351; d) M. Suresh, A. Gosh, A. Das, Chem. Commun. 2008, 3906; e) J. Andreasson, S. D. Straight, T. A. Moore, A. L. Moore, D. Gust, Chem. Eur. J. 2009, 15, 3936-3939; f) M. Kumar, A. Dhir, V. Bhalla, Org. Lett. 2009, 11, 2567-2570.

[7] a) J. Andreasson, S. D. Straight, T. A. Moore, A. L. Moore, D. Gust, J. Am. Chem. Soc. 2008, 130,11122-11128; b) H. Tian, Angew. Chem. 2010, 122, 4818-4820; Angew. Chem. Int. Ed. 2010, 49, 4710-4712.

[8] a) G. De Ruiter, E. Tartakovsky, N. Oded, M. E. van der Boom, Angew. Chem. 2010, 122, 173-176; Angew. Chem. Int. Ed. 2010, 49, 169-172; b) U. Pischel, J. Andreasson, New J. Chem. 2010, 34, 2701-2703; c) U. Pischel, Angew. Chem. 2010, 122, $1396-$ 1398; Angew. Chem. Int. Ed. 2010, 49, 1356-1358; d) G. de Ruiter, L. Motiei, J. Choudhury, N. Oded, M. E. van der Boom, Angew. Chem. 2010, 122, 4890-4893; Angew. Chem. Int. Ed. 2010, 49, 4780-4783.

[9] a) R. Baron, O. Lioubashevski, E. Katz, T. Niazov, I. Willner, Angew. Chem. 2006, 118, 1602-1606; Angew. Chem. Int. Ed. 2006, 45, 1572-1576; b) T. Niazov, R. Baron, E. Katz, O. Lioubashevski, I. Willner, Proc. Natl. Acad. Sci. USA 2006, 103, 17160-17163; c) G. Strack, M. Ornatska, M. Pita, E. Katz, 
J. Am. Chem. Soc. 2008, 130, 4234-4235; d) M. Privman, T. K. Tam, M. Pita, E. Katz, J. Am. Chem. Soc. 2009, 131, 1314-1321.

[10] a) T. Gupta, M. E. van der Boom, Angew. Chem. 2008, 120, 2292-2294; Angew. Chem. Int. Ed. 2008, 47, 2260-2262; b) T. Gupta, M. E. van der Boom, Angew. Chem. 2008, 120, 5402 5406; Angew. Chem. Int. Ed. 2008, 47, 5322-5325; c) S. Silvi, E. C. Constable, C. E. Housecroft, J. E. Beves, E. L. Dunphy, M.
Tomasulo, F. M. Raymo, A. Credi, Chem. Eur. J. 2009, 15, $178-$ 185.

[11] F. M. Raymo, S. Giordani, Proc. Natl. Acad. Sci. USA 2002, 99, $4941-4944$.

[12] F. Remacle, S. Speiser, R. D. Levine, J. Phys. Chem. B 2001, 105, $5589-5591$. 